\title{
ELECTRONIC TENNIS OFFICIATING: \\ LOW COST, ACCURATE AND RELIABLE SOLUTIONS
}

by

\author{
Andrew Hawling \\ B.Comm. (Hons.), University of Ontario Institute of Technology, 2015
}

\begin{abstract}
A Major Research Project
presented to Ryerson University

in partial fulfillment of the

requirements for the degree of

Master of Digital Media

in the Program of Digital Media
\end{abstract}

Toronto, Ontario, Canada, 2017

CAndrew Hawling, 2017 


\section{AUTHOR'S DECLARATION FOR ELECTRONIC SUBMISSION OF A MRP}

I hereby declare that I am the sole author of this MRP. This is a true copy of the MRP, including any required final revisions.

I authorize Ryerson University to lend this MRP to other institutions or individuals for the purpose of scholarly research.

I further authorize Ryerson University to reproduce this MRP by photocopying or by other means, in total or in part, at the request of other institutions or individuals for the purpose of scholarly research.

I understand that my MRP may be made electronically available to the public. 


\title{
ELECTRONIC TENNIS OFFICIATING: \\ LOW COST, ACCURATE AND RELIABLE SOLUTIONS
}

\author{
Master of Digital Media, 2017 \\ Andrew Hawling \\ Master of Digital Media, Ryerson University
}

\begin{abstract}
The goal of this project was to research an electronic tennis officiating system that was low cost, accurate, and reliable. To do this, professional practices and literature were reviewed to identify what was already known and being implemented in the market. A basic proof of concept, in the form of a foot fault detecting system, was built in order to find out if a larger system could realistically be built. Then, a thorough investigation of components, including sensors, microcontrollers, wireless devices, cases, holders, and alert systems was performed to better understand the underlying technologies and suitability in a tennis officiating setting. Sensors were tested on a full-scale tennis court to identify the best possible option for a final design based on accuracy, cost, ease of use, set-up time, reliability, and size. Additionally, a plan to develop and commercialize the system was examined, taking into consideration relevant costs and restraints. Finally, a scale model of the full system was put together, showcasing the components previously studied and providing end users with an idea of how it would work.
\end{abstract}




\section{Acknowledgements}

I would like to thank my parents, Patti and Chris, for supporting me throughout my educational endeavours. I also want to thank Rob Blain for being an amazing physical computing instructor and supervisor. Without your lessons and support, this project would not have been possible. 


\section{Table of Contents}

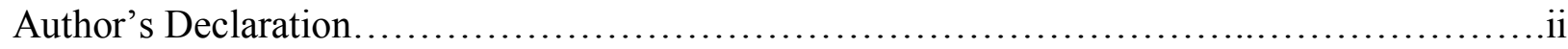

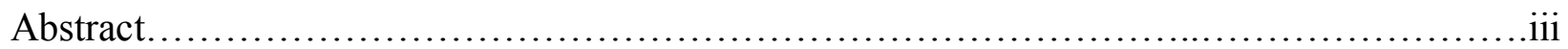

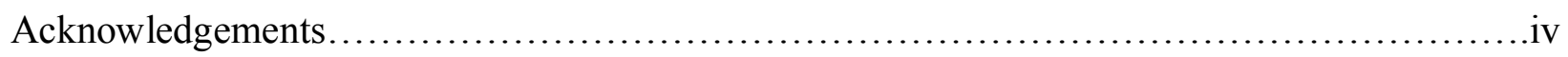

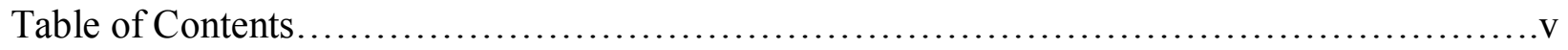

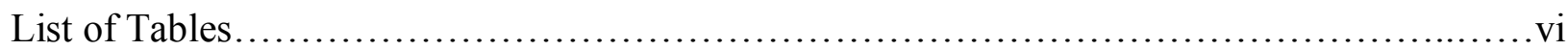

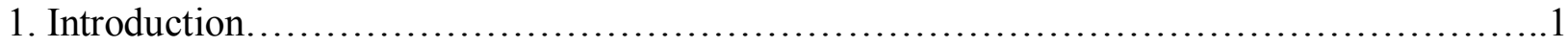

2. Review of the Literature and Professional Practice......................................

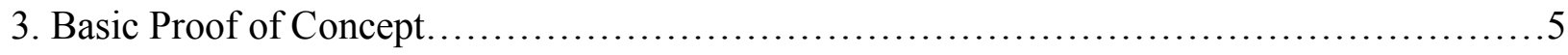

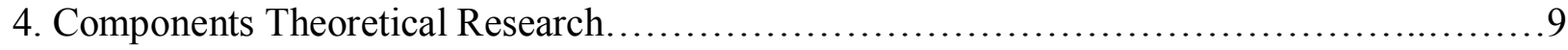

5. Components Practical Research................................................... 20

TABLE 1: Evaluation and Weighted Comparison of Sensors for Tennis Balls and

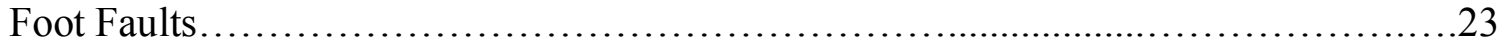

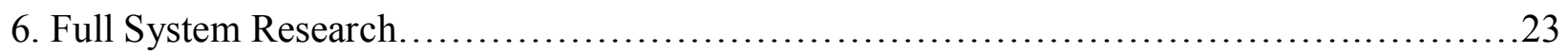

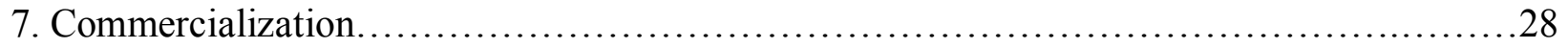

TABLE 2: Electronic Tennis Officiating System Components Costs.....................30

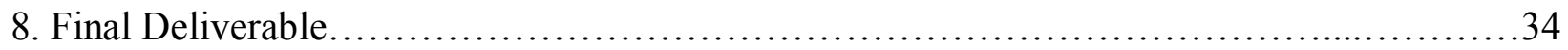

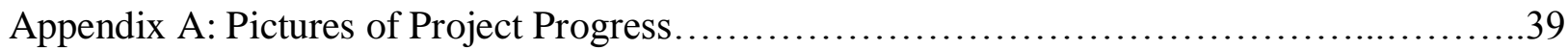

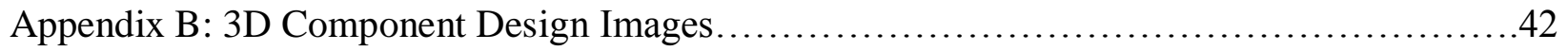

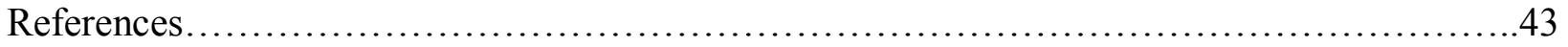




\section{List of Tables}

TABLE 1: Evaluation and Weighted Comparison of Sensors for Tennis Balls and Foot Faults TABLE 2: Electronic Tennis Officiating System Components Costs 


\section{Introduction}

Small and medium sized tournaments and events around the Canada rely on the honour system for officiating matches, where players call their own lines. In some cases, they will have a budget for a few roving umpires or chair umpires that can help keep matches running smoothly and overrule egregious calls. However, since they are often far away from the lines themselves, it is difficult to make decisions, leading to a lot of frustration for players and fans alike.

There are two alternatives to making line calls on the market today; the hiring of a full crew of umpires, and the installation of a Hawkeye digital officiating system. With umpires, a tennis federation, such as the Ontario Tennis Association, Tennis Canada or the International Tennis Federation must be called in to supply trained officials that meet regular evaluation standards. These officials must be paid at minimum $\$ 60$ per day each and there must be at least two crews of line umpires for each court (Tennis Canada Officiating, 2017). In addition, a different chair umpire must oversee each match, which costs another $\$ 110$ per day each (Tennis Canada Officiating, 2017). At a very modest tournament involving 12 matches across 2 courts, this would work out to $\$ 3000$ per day.

Conversely, if a tournament wishes to implement a challenge system, they must pay Hawkeye and Flightscope a minimum of $\$ 10,000$ per court for a week's worth of matches (Ginn, 2011). This includes the extensive setup and testing of high speed cameras as well as regular operation of the video replay system by a team of technicians. Even with all of this done, it would still be up to players and a chair umpire to make real time calls and would only involve the digital system with a replay challenge.

There needed to be a better way small and medium sized tournaments could get better officiating for a lower price than both staffing line umpires or having Hawkeye installed on 
courts. This new system would make it cheaper and easier for accurate, real time line calls, therefore improving the quality of matches and giving peace of mind to both players, roving officials and event organizers. Using microcontrollers, a few consumer grade sensors and an alerting control panel, the fundamentals of junior and amateur tennis could be changed forever.

\section{Differentiating Factors}

There are a few key elements that make this system unique in the marketplace today. Firstly, it can make calls on all lines in real time. Hawkeye, which is the most widely used digital officiating system, can only correct calls after the fact through a challenge system (Hawk-Eye Innovations, 2015, p. 3). This real-time line calling will lead to less match interruptions and greater peace of mind for both players and officials.

The new system could also be used by a chair or roving umpire themselves. Other systems require several technicians and broadcast professionals be on hand during matches in order to use the advanced challenge software (Hawk-Eye Innovations, 2015, p. 3). The system to be created would therefore cut down on complexity and labour costs for tournaments.

Furthermore, the proposed system would use low cost, consumer grade sensors and microcontrollers. The most expensive potential component would be a LiDAR rangefinder, at a cost of \$200 (CAD) each (Robot Shop, 2017). Other systems utilize camera equipment and computer software that can cost hundreds of thousands of dollars, and which costs tournaments tens of thousands of dollars for installation and operation (Ginn, 2011).

Additionally, the new system to be built would put sensors directly beside the court. This has the potential to increase accuracy due to the closer proximity to the ball and lines. Other 
systems require the installation of several cameras spread throughout the court at a height of $10 \mathrm{ft}$ or more (Hawk-Eye Innovations, p. 3).

Foot faults will also be detected in this system for the first time in amateur or professional tennis. At larger tournaments, line umpires are tasked with looking at the baseline during service, but this is rarely done at smaller events. The electronic systems on the market today only look at balls being in and out and cannot review challenges regarding feet being out of position.

Finally, the proposed system would use the newest and most advanced technologies on the market today, leading to improved accuracy. LiDAR can be more accurate as some models can emit 167,000 pulses per second (Indian Institute of Technology Kanpur, n.d.). Also, precision ultrasonic sensors can measure distances within a margin of only 1mm (Garmin, 2016). Hawkeye's system relies on outdated camera equipment that can be interfered with by sunlight, artificial light, shadows and wind (Hawk-Eye Innovations, 2015, p. 2).

\section{Review of Literature and Professional Practice}

The original inspiration for undertaking this project was the Cyclops, originally used at large professional tennis events during the early 1980s (Greenman, 2000). The system, created by Bill Carlton of Malta, relied on five infrared sensors positioned 10mm above the court; one on the inside of the service line and four on the outside (BBC Sport Academy, n.d.). If a ball landed outside of the service line, the system would emit a loud beeping noise so the chair umpire or line umpire would know what the proper call was (BBC Sport Academy, n.d.). While the technology was improved over the years, it was eventually phased out and replaced by the Hawkeye replay system for a few key reasons. Firstly, the margin of error was significant given the fact the individual infrared beams were several centimetres wide, leaving room for obviously 
wrong calls being made (BBC Sport Academy, n.d.). Furthermore, because of the sensitivity of the device, other things, such as pieces of dirt and small insects, would often set it off, leading players to have to replay points because of the interruption (Roberts, 1995). It was thought that by implementing a similar concept of putting sensors within view of lines, but by using more accurate and reliable technology such as LiDAR, the goal of creating the lowest cost digital officiating aid on the market could be achieved.

The most notable professionally used system on the market today is Hawkeye. This technology relies on ten video cameras positioned above and outside the court in order to track the movement and trajectory of the ball during points (Hawk-Eye Innovations, 2015, p. 3). From this information, the system calculates a bounce mark in relation to the lines of the court in order to determine whether it was in or out (Hawk-Eye Innovations, 2015, p. 2). In practice, officials use Hawkeye when a player disagrees with a call made by either the chair umpire or line umpires. Once a challenge is requested, a team of five technicians work to find the specific ball strike being disputed, and then display a 3D video that can be played in the umpire's tablet and/or large screens in the stands (Hawk-Eye Innovations, 2015, p. 3). At the end of the video, the ball mark is shown along with the accompanies correct in or out call (Hawk-Eye Innovations, 2015, p. 2).

While this technology is used at over 80 tournaments around the world, and has continually improved over the last decade, it still presents problems (Hawk-Eye Innovations, 2015, p. 3). First and foremost, there are issues with the underlying accuracy of the line calls and bounce marks. After extensive testing the International Tennis Federation determined that the average margin of error is $2.6 \mathrm{~mm}$ (Hawk-Eye Innovations, 2015, p. 2). While this may not seem like a lot to most people, it can have significant implications for players and line umpires during 
the match. Furthermore, these accuracy issues can be amplified due to the limitations of the highspeed video cameras used. Outside factors such as sunlight, artificial light, shadows and wind can cause issues with what each camera sees, therefore making calls even less accurate on certain days. Finally, this system cannot be used in real-time to make calls on balls. As a result, a point may have to be replayed if the Hawkeye system disagrees with a chair or line umpire, therefore increasing match times and adding to player frustrations.

Because of all of this, it was thought that taking similar technology and moving it down to the playing surface might help cut down on potential issues. This way, the margin of error could be significantly reduced from less potential outside interference and closer proximity to the court and ball. Also, corrections to calls could be made in less than a second, so there is less slowdown to the math and players have greater peace of mind.

\section{Basic Proof of Concept}

A very basic practical model of a working officiating system will be created. This will be in the form of a foot fault detecting system, where a user will be alerted if a foot crosses the baseline or if a ball hits the net cord. An on and off button will be used by the official to control when the system is operational and switches will control which sensors are on for different parts of the court. If a specified event happens, it will register an alert in the form of an LED lighting up or a buzzer going off. There will be some use of wireless technologies, most likely for the net cord vibration sensor.

This part of the project is done to demonstrate that this type of system is actually feasible and practical. Furthermore, it will provide a better idea of how to proceed in future research when building a more substantial system. Finally, it will provide the opportunity to test out 
hardware and other sensors to help decide what should be used later on and what problems to look out for.

\section{Components}

There will be several elements included in this system design including an Arduino Uno microcontroller, full sized breadboard, jumper wires, a Garmin LiDAR rangefinder, an IR beam break sensor, two switches, a button, two LEDs (one green and one red), several resistors of varying strengths, a Bluetooth bean equipped with a buzzer, painter's tape, a whiteboard with scale model tennis court lines and an adjustable table tennis net and posts.

\section{How It Works}

One switch controls whether the sensor is alerting for the far or near side of the court, while the other one controls whether or not the system is alerting for the right or left side of the court. When the button is pressed, and held down, the system initiates and the green light is turned on. If a foot crosses the line for the selected part of the court, the red light turns on to alert the official of a fault. If the ball hits the net and it vibrates, the Bluetooth bean blinks a red light twice and the buzzer activates.

\section{Building/Set-Up}

A breadboard was implemented as the main user input point for simplicity, as it could be handheld during operation. Tape was used to secure the IR and LiDAR sensors to the whiteboard as it made repositioning for accuracy much easier. Significant soldering was done to properly connect component cables with longer jumper wires. Jumper wires were also wrapped around the 
Bluetooth bean on the net to secure it in place as a holding device could not be found that would fit it. The ' $\mathrm{C}$ ' programming language was used to code the entire project, including the Arduino Uno and the Bluetooth bean. Before the final version of the build, a baseline test was performed for the LiDAR, which included comparing I2C and PMW setup as well as distance threshold measuring based on the whiteboard lines.

\section{Problems/Issues}

It took a long time to get the sensors to alert directly on the line and involved the tweaking of code and changing the physical positioning of the sensors. The beam break system was often unreliable as slight positioning changes made it inoperable. The LiDAR gave readouts that fluctuated a few times per second and when testing was done on calls near a distance threshold, false positive and negative results were seen. It was quite difficult to write code for the 3 axes of the Bluetooth bean sensor as integrating all 3 values and finding a good vibration threshold required a lot of trial and error as well as rewriting. Finally, soldering with a lead-free product was more difficult and time consuming than expected. It required a much higher temperature on the soldering iron and the solder did not flow very well, requiring several attempts for each component.

\section{Insights for Later Stages of Project}

There were a few key insights taken from the entire foot fault system building process that will be uses in future parts of the project. First is that the system should be built and tested the system one part at a time. This would make it easier to identify problem areas without having to rewire, reposition sensors and rewrite code. Also, a PMW setup as opposed to an I2C setup 
should be used for more advanced sensors when possible as it is much less complex and easier to use. Furthermore, the system requirements should be drawn or written out beforehand in order to make it easier to convert ideas into actual code later. Additionally, a study of individual components should be conducted before implementing them into the system. This could include reading manuals, forums and guides, watching videos and testing out libraries. This will make troubleshooting much faster due to having a better overall understanding of what each component does. Finally, diagrams or pictures should be routinely taken as the setup goes along. This will make it easier to revert back to previous versions, take the system apart and eventually put it back together.

\section{Improvements to be Made}

A more secure way of holding sensors in place is needed in order to make it easier to take components off and make slight adjustments. Also, an attempt will be made to integrate the Bluetooth bean net sensor into the rest of the system so the alert only goes off during player service. This step to use more wireless technologies will be important to ensure the system is less cluttered and provide greater positioning freedom. User inputs will be made more separate from the breadboard and Arduino in order to lower the risk of wires accidentally being disconnected and make it easier for an official to control the system. Finally, the utilization of multiple alert components will be tried so the official can see more than one alert at the same time. 


\section{Components Theoretical Research}

\section{$\underline{\text { Sensors }}$}

\section{$\underline{\text { LiDAR Rangefinder }}$}

This device "measures distance by calculating the time delay between the transmission of a near-infrared laser signal and its reception after reflecting off of a target" and is based on the speed of light (Garmin, 2016). It starts by performing a receiver bias correction sequence in order to adjust for lighting conditions (Garmin, 2016). Then, it provides a serial distance measure with a series of laser pulses, based on the reflection that is received (Garmin, 2016).

The device has a wide operating temperature, from $-20 \mathrm{C}$ to $+60 \mathrm{C}$, so the operator does not have to worry about malfunctions on especially hot days (Garmin, 2016). It also has a very substantial range of 40m, providing greater positioning freedom (Garmin, 2016). It has very good accuracy at very long distances, with a $+/-1 \mathrm{~cm}$ resolution and a $2 \mathrm{~mm}$ beam diameter (Garmin, 2016). It features fast data capture with up to 500 readings per second (Robot Shop, 2017). Additionally, it has two different measurement and set-up options in the form of I2C (inter-integrated circuit) and PMW (pulse width modulation options), which provides greater freedom in system construction (Garmin, 2016). Furthermore, it is small in both height and weight, with measurements of only $2 \mathrm{~cm} \mathrm{x} 4.8 \mathrm{~cm} \times 4 \mathrm{~cm}$ and $22 \mathrm{~g}$ in total (Robot Shop, 2017). The device will not be affected by lighting conditions or weather, meaning it can be used indoors and outdoors and will have no negative effects from wind or cloud cover (Indian Institute of Technology Kanpur, n.d.). Finally, the laser used within is eye safe so players and officials will not need to wear special goggles while it is in use (Garmin, 2016).

The LiDAR rangefinder is quite expensive, starting at \$199.99 each, with the price only down to $\$ 169.99$ each when ordering over 100 (Robot Shop, 2017). There is also the potential 
for interference should nearby infrared wavelengths be present (Garmin, 2016). Finally, the readings may not be accurate should the sensor lenses, ball or shoes have water droplets on them (Garmin, 2016).

\section{$\underline{\text { IR Distance Sensor }}$}

This device uses a pair of sensors within one housing; one that emits an infrared beam and the other that receives it (Carnegie Mellon University, n.d.). The IR beam hits whatever is in front of it, bounces off, and returns to the system (Carnegie Mellon University, n.d.). Based on the angle of the beam, it calculates and records the relative distance of the object (Carnegie Mellon University, n.d.).

Such devices are relatively inexpensive, with some models starting at under $\$ 20$

(Adafruit, 2015). Finally, they are small in size, usually being only a few centimeters long and weighing around $10 \mathrm{~g}$ (Adafruit, 2015).

However, most models are limited in range, with a maximum for most consumer level models being 5 to 10 meters (Adafruit, 2015). Because of this, they could most likely not be used on the sidelines and might have to very close to the court on the baselines and service lines. They can also be unreliable in an outdoor environment due to the fact weather and sunlight can affect their readings (Arduino, 2013). Dark and bright conditions, as well as high temperatures, may cause regular malfunctions (Adafruit, 2015). Additionally, they are known to be noisy during operation, potentially being disruptive to players and officials if close to a court (Adafruit, 2015). Lastly, the lenses must be kept completely clean at all times, with dirt, water or other residue causing bad readings (Sharp, n.d.) 


\section{IR Beam Break}

This device features two different components; one that emits and infrared signal and one that receives it (Adafruit, n.d.). If the IR input or output are slightly moved, or something is placed between them, a signal is sent to the microcontroller (Adafruit, n.d.).

It is quite simple to use due to easy set-up, a digital output of either a 1 or a 0 and requiring simple code to function (Adafruit, n.d.). The device is also available in many different sizes that can work for different distances (Adafruit, n.d.). Finally, it is very cheap, with some entry level models available for under $\$ 10$ (Adafruit, n.d.).

The device requires two different parts on different sides of the court to function, which means more set-up time. It also does not measure distance, so it could not be customized to only alert to certain parts of the court and would therefore be prone to interference from players' feet, balls, dirt, insects and garbage. Additionally, there can be significant interference from varying weather conditions (Arduino, 2013). Dark and bright conditions, as well as high temperatures, may cause regular malfunctions (Adafruit, n.d.). Lastly, it is usually only rated to work at smaller distances, which means it may not work at all for a full-sized court, or it might have to be positioned closer to lines, making it a tripping hazard (Top Ten Reviews, 2016).

\section{$\underline{\text { Precision Ultrasonic }}$}

This sensor sends out a wave of a certain frequency, and once it hits an object, the wave returns and is measured by the sensor (Carnegie Mellon University, n.d.). It calculates distance based on the amount of time it took for the wave to return while factoring in the known speed of light through the air: $344 \mathrm{~m} / \mathrm{s}$ (Carnegie Mellon University, n.d.). 
It has a very wide operating temperature, from $-40 \mathrm{C}$ to $+65 \mathrm{C}$, so it would not be affected by warm weather or hot courts (Robot Shop, n.d.). The device is also very accurate, with a resolution of just $1 \mathrm{~mm}$ and a very narrow scope (Robot Shop, n.d.). Furthermore, it will give good results regardless of the weather conditions as it takes into account temperature, humidity and ambient noises (Maxbotix, 2012). It is quite small in size, being only around $6 \mathrm{~cm}$ by $4 \mathrm{~cm}$ (Maxbotix, 2012). Additionally, it provides many output options, including analog voltage, serial and pulse width, and requires between only 2.7V and 5.5V to operate (Maxbotix, 2012). Finally, it is constructed using very durable plastics, meaning it will hold up to significant wear and tear (Robot Shop, n.d.).

Most models have a somewhat limited distance range, topping out around $5 \mathrm{~m}$ (Robot Shop, n.d.). This would mean it could most likely not be put on the sidelines and would have to be placed very close to the court for service and baselines. It can also be affected by outside acoustic or electrical noise, which may result in bad distance readings (Maxbotix, 2012).

Furthermore, the wires have to be soldered onto the sensor itself, meaning the connections are less reliable and more maintenance would have to be performed regularly (Maxbotix, 2012). Lastly, it has somewhat slow measurement times, with a refresh rate of around $140 \mathrm{~ms}$ depending on the mode (Maxbotix, 2012). This translates to only 7.14 readings per second, meaning it may miss fast balls, especially on serves.

\section{$\underline{\text { Microcontrollers }}$}

\section{$\underline{\text { Arduino Uno }}$}

This device is a simple, low-cost, open source microcontroller motherboard used for basic prototyping (Di Justo, 2015). It can be programmed in a variety of languages, including C, 
C++, Java and Python (Electrical Engineering Stack Exchange, 2011). It includes a voltage regulator, 14 digital I/O pins, 6 analog pins, 32KN of flash memory and 2KB of RAM (Arduino, n.d.). The device is only $6.86 \mathrm{~cm}$ wide and weighs just $25 \mathrm{~g}$ (Arduino, n.d.).

It is extremely easy to prototype with due to the fact it works right out of the box, includes a basic programing interface with a debugger and features an on-board $5 \mathrm{~V}$ power regulator to avoid overloading (Arduino, n.d.). It was also utilized as the main device throughout the Physical Computing class during the winter 2017 semester, meaning usage should be easier. The device is very affordable, at just $\$ 26.99$ retail and a few dollars extra for a USB cord (Arduino, n.d.). Additionally, there is a large amount of support available when needed as the Arduino organization itself provides a lot of instructions and tutorials, plus the programming community is very large and helpful. Finally, it features plastic connection headers, so no soldering is required and the connections are therefore more stable (Engineering Experiences, 2016).

However, it is limited in functionality as it can mostly only handle small, repetitive tasks (Di Justo, 2015). The device is low in overall storage capacity and cannot have very much code loaded onto it at one time (Arduino, n.d.). Also, the number of components used need to be kept to a minimum due to the small size and limited number of connection points (Engineering Experiences, 2016). Lastly, you need to buy many peripherals in order to increase its functionality, including shields, beans, LEDs and sensors, which can make the cost more significant (Arduino, n.d.). 


\section{RaspberryPi 3}

This basic, low, cost, Linux based computer can be used as a standalone multimedia device or for prototyping (Raspberry Pi Foundation, 2016). It features a quad core CPU, 1GB of RAM, Bluetooth 4.1 and Bluetooth Low Energy (BLE), Wi-Fi and Ethernet ports, 4 USB ports, an HDMI port, 40 GPIO pins, an audio jack, camera and display interfaces, a micro SD card slot and a 3D graphics core (Raspberry Pi Foundation, 2016).

It has built-in Wi-Fi and Bluetooth capabilities, so additional shields are not necessary for wireless capabilities (Raspberry Pi Foundation, 2016). It is also very powerful, therefore enabling it to handle more complex programs and even multiple programs at the same time (Di Justo, 2015). The device also has greater peripheral options, with 40 total pins and built-in camera, audio and display interfaces (Raspberry Pi Foundation, 2016). Additionally, there is a large developer community, which means there are a lot of tutorials and guides on the internet for free, as well as forums that provide answers to technical problems quickly (Raspberry Pi Foundation, 2016). The storage capacity is quite significant due to there being many options available with several gigabytes on included. Finally, it can be programmed using several languages, including Python, C++, Java, Scratch, Ruby, Javascript and Perl, which makes development much more flexible (Dikmans, 2015).

There is a larger learning curve for this device due to the fact it was not used in the Physical Computing class at all. Also, it is generally not seen as beginner friendly due to the fact it requires greater overall technical proficiency to operate (Orlin, 2012). Additionally, it must go through an extensive setup before being used, which requires downloading new software and formatting micro SD cards (Orlin, 2012). Furthermore, it has very specific power requirements, so small surges can completely fry the board and make it unusable (Orlin, 2012). Lastly, it is 
more expensive than other options, with a retail price of \$51.99 in a retail setting (Di Justo, 2015).

\section{Wireless Devices}

\section{Punch Through Light Blue Bean+}

This device is a small microcontroller that can be programmed wirelessly through a Bluetooth Low Energy (BLE) connection (Punch Through, n.d.). It can be programmed with several different languages using Windows, Mac OS, iOS and Android systems (Punch Through, n.d.). It comes with a built-in battery that can be recharged via USB and outputs either $5 \mathrm{~V}$ or 3.3V at any time (Punch Through, n.d.). The standard onboard sensors and components include an accelerometer, RGB LED, temperature monitor, Grove ports and 16 GPIO connectors (Punch Through, n.d.).

Several of these devices can be used at the same time, meaning they could be put on sensors around the court for an entirely wireless system (Punch Through, n.d.). It is much less complex than similar Wi-Fi setups because Bluetooth creates its own local network and does not have to be integrated into existing on-site frameworks (Punch Through, n.d.). The device is very reliable due to it being immune from typical Wi-Fi problems, including network outages and slow speeds (Punch Through, n.d.). It can also be fully integrated with an Arduino setup, meaning similar sketches can be uploaded to the bean, and Arduino sketches can be linked to work with the beans directly (Punch Through, n.d.). The bean comes with its own built-in libraries, meaning it can use existing processes to speed up the coding process of complex programs (Punch Through, n.d.). Furthermore, it comes with free loading software, making it easier and faster to upload code to the device (Punch Through, n.d.). Finally, it has long range 
capabilities of over $300 \mathrm{~m}$, so it could be reprogrammed or updated from across a facility (Punch Through, n.d.).

However, the bean has a very small battery capacity of only $600 \mathrm{maH}$, meaning it can only be used for a few hours at a time and would require frequent recharging or battery placement. Also, it is more difficult to use with Mac computers because security software does not allow for the full use of Bluetooth ports (Punch Through, n.d.). In order to get around this, a separate Processing file on a computer would have to be used as a workaround.

\section{Wireless Shields}

These are "modular circuit boards" that can attach to a microcontroller to provide it with additional functionalities (Sparkfun, n.d.). They are available for Wi-Fi, NFC, RFID, IR, Bluetooth 3.0, BLE and cellular uses (Sparkfun, n.d.). The shields increase the size of the prototype, but make it more useful for more complex applications. The cost for different models varies, but most are between $\$ 10$ and $\$ 100$ each (Sparkfun, n.d.).

Shields allow for a microcontroller to be programmed without being connected to a computer, so code can be changed whenever needed from far away. Also, they provide greater positioning freedom on court as the microcontroller would no longer need to be near the sidelines for a technician to reprogram it.

They often consume a large amount of power, meaning the microcontroller and shield would need to be near outlets or have large batteries to operate (Sparkfun, n.d.). Also, they increase the overall size of the device, making it more difficult to fit in small places. Finally, they present a greater likelihood of malfunction as adding more components to a design can provide more opportunities to go wrong (Sparkfun, n.d.). The chances of problems occurring are also 
increased due to the fact headers must be soldered on, making for unreliable and unstable connections, as well as the potential for frequent repairs.

\section{$\underline{\text { Cases/Holders }}$}

\section{$\underline{3 D \text { Printed Cases/Holders }}$}

In this process, a machine turns a 3D computer design into a physical object (Walker, 2013). The system breaks down the design into individual slices and prints with the chosen material from the bottom up (Walker, 2013). It can use metals, including sintered powdered metals, stainless steel, bronze, gold, nickel, aluminum and titanium (Giges, 2014). Carbon materials, such as carbon fibre, nanotubes and graphene are also an option (Giges). Lastly, many plastics can be used for printing, including Acrylonitrile Butadiene Styrene (ABS), Polylactic Acid (PLA) and Polyvinyl Alcohol (PVA) (3D Printing For Beginners, 2013).

Using this method, very little construction is required, as the entire object can be printed in one session. Also, many different materials can be used to print, including several types of plastics and light metals.

However, this process is very time consuming, as the design process may take hours and the printing of even small designs can take as long as a day to make (Walker, 2013). Furthermore, there is a significant chance of imperfections, especially where long straight sides may have small bends in them (Walker, 2013). The construction of these creations may also be flimsy due to the fact the materials at my disposal in Ryerson are mostly light plastics. Lastly, there is a relatively high cost associated with 3D printing, with the average dollar amount spent per unit being substantially higher compared to other methods of construction (Walker, 2013). 


\section{Laser Cut Cases/Holders}

To begin this process, very high intensity light passes through carbon dioxide gas and a series of mirrors (ESAB, 2013). Then, the beam passes through several lenses that make the it even stronger and smaller, so it is the desired diameter for the project (ESAB, 2013). Then, the beam passes through compressed oxygen or nitrogen gas, passes through a nozzle and comes out into the work surface $(\mathrm{ESAB}, 2013)$. The laser heats, melts and vaporizes the material while moving in all directions based on a computer design, therefore leaving the material with the desired cuts (ESAB, 2013). There are many materials that can be used in laser cutting, including Plexiglas, ABS, Mylar, Styrene, stainless steel, foam, wood and cloth (Pololu Robotics and Electronics, n.d.).

Laser cutting is very fast in comparison to other methods due to the fact it is only slicing the material instead of moulding it $(\mathrm{ESAB}, 2013)$. Also, there is a very low risk of imperfections since the laser can cut things to exact specifications (ESAB, 2013). Additionally, there are many materials to choose from, providing a great deal of design flexibility (Pololu Robotics and Electronics, n.d.).

This method may require a lot more construction than others due to the fact all of the pieces cut eventually have to be put together properly. The laser cutter can be quite dangerous to use as well because it has the potential to cause severe skin burns in the event of an accident (ESAB, 2013). 


\section{Alert Systems}

\section{$\underline{\text { LED Light Board }}$}

Several LED lights are strung together to form a rectangular sheet, sometimes covered in transparent plastic. Different LEDs or groups of LEDs can be programmed to light up in varying colours to notify individuals of something.

This system is very easy to see out of someone's peripheral vision, meaning an official could still be looking at the match and while being alerted to a line call being made. Also, it is very easy to program for, especially using online tutorials that are provided on many different websites. Finally, it is quite easy to hold, meaning little construction would have to be done to make it usable to an individual.

However, this type of device can take up a lot of space, making it potentially difficult for officials to hold on the sidelines or in the chair. Also, some models use a lot of power, which would put a strain on the system's batteries.

\section{$\underline{\text { Buzzers }}$}

Code is written to make electricity flow through the device when a sensor transmits a certain message. It then makes an audible noise of varying intensities and pitches.

Using buzzers in the system would not require an official to look at the alert device, so they can be totally free to focus on the match and still be alerted to line calls.

These devices can be quite noisy and may therefore be disruptive to players or people on other nearby courts. 


\section{$\underline{\text { LCD Display }}$}

A screen similar to those seen on televisions and graphing calculators is used in order to display messages. A microcontroller can be programmed to tell the display what to show on different parts of the screen at certain times. Lines, shapes, words and numbers can all be utilized within the system.

This screen is very user friendly, as it is easy to read and can easily fit in the palm of the hand. However, the screen may be difficult to see during a match as there is very little backlighting available on most models. They would have to stop paying attention to the match for a second or two to look down and read what was called. This device is also more difficult to program than other alerting methods as it takes more code to make it work properly. Also, microcontroller compatible models cannot have much writing on them as the screens are quite small in terms of width and length. Finally, the screens are delicate, so if one is dropped or hit, there is a high likelihood it would break or malfunction.

\section{Components Practical Research}

In order to test the sensors, some custom Arduino code was programmed for each one involving a LED turning on when a reading under a certain threshold was seen. The distance was also displayed in the serial monitor on the connected computer. In order to do this, online tutorials, product guides and sensor libraries were used in order to ensure proper functioning. 40 tennis ball throws/drops on a full-sized tennis court were used to evaluate the sensors; 10 drops from inside 1 meter, 10 drops outside 2 meters, 10 high speed throws from inside 1 meter, and 10 high speed throws from outside 2 meters. Inaccurate throws and drops were taken out of consideration in order to lessen the effect of human error on results. 


\section{LiDAR Rangefinder}

This sensor required the most research out of all of the ones tested as it is much more complex in terms of operation and coding compared to any other component It had been used in courses previously. Eventually, some tutorials and libraries found on the internet were consulted to customize the code for testing.

It was noticed that the readings from the LiDAR came in extremely fast, so a slight increase the delay was implemented in order to be able to read the distances in the serial monitor. The accuracy of distance measurements was very good, as it provided reliable results at a few centimeters as well as at several meters away. The distances seen were usually only off by a few millimeters compared to what had been recorded using a measuring tape. However, at times readings jumped around by approximately 5 millimeters within one second. It was also noticed that the beam was very narrow, and balls thrown even slightly over the line were not picked up, which is what had been intended.

\section{IR Distance Sensor}

This sensor was very easy to setup and operate due to the fact it is frequently used by hobbyists, which meant there were many instructions, guides and forum posts on the internet. The readings during testing appeared in the serial monitor at a moderate speed, with only a slight delay compared to the impact of the ball on the court. The accuracy was decent at short and medium range distances, with accuracy on calls within a few centimeters. This was most likely due to the fact the beam was slightly wider than other sensors tested. However, the accuracy was poor at longer distances, when the device gave clearly wrong serial readings based on the ball position. 


\section{$\underline{\text { IR Beam Break }}$}

The device was by far the easiest to setup due to its very simple functionality, meaning it was working with only a few lines of code written. The digital readings were the fastest of any sensor tested. The accuracy was impressive at short and medium distances due to the narrow width of the beam. When setup on the line, it could reliably make correct close calls. However, it was less reliable at longer distances. Even when both ends were setup straight across from one another, it would sometimes give false break readings.

\section{Precision Ultrasonic}

This sensor was somewhat difficult to setup for operation. There was a small margin of error when soldering pins onto ports due to them being so close together, and example code for the specific sensor model was hard to find on forums and other websites. Readings were very slow, meaning a change in ball position was not picked up for almost one second at times during testing. Its accuracy was terrible at short distances, and readings in the serial monitor would often not change for distances less than 1 meter. Its accuracy was slightly better, but still poor, at longer distances, with significant discrepancies between distances measured using a tape measure.

\section{$\underline{\text { Summary and Evaluation }}$}

In order to evaluate and compare the different sensors used, a score from 1 to 10 was given for each sensor according to different categories, including accuracy, cost, ease of use, setup time, reliability and size. 
To better analyze the results according to the importance of different categories in the final system, a weight was given to each area. Accuracy was worth $25 \%$, reliability was worth $22 \%$, cost was worth $20 \%$, ease of use was worth $16 \%$, setup time was worth $10 \%$, and size was worth $7 \%$.

In the end, in terms of both unweighted and weighted scores, the LiDAR rangefinder was the best, followed by the IR beam break, followed by the IR distance sensor, followed by the precision ultrasonic sensor.

\section{TABLE 1:}

\begin{tabular}{|c|c|c|c|c|c|c|c|c|}
\hline \multicolumn{9}{|c|}{ Evaluation and Weighted Comparison of Sensors for Tennis Balls and Foot Faults } \\
\hline & \multicolumn{6}{|c|}{ Decision Criteria } & \multicolumn{2}{|c|}{$\underline{\text { Score }}$} \\
\hline & Accuracy & Cost & Ease of Use & $\underline{\text { Set-Up Time }}$ & Reliability & $\underline{\text { Size }}$ & Unweighted & Weighted \\
\hline Weightings & $25 \%$ & $20 \%$ & $16 \%$ & $10 \%$ & $22 \%$ & $7 \%$ & / & / \\
\hline LiDAR Rangefinder & 9 & 4 & 8 & 9 & 9 & 7 & 46 & 7.7 \\
\hline IR Distance & 5 & 6 & 7 & 8 & 7 & 8 & 41 & 6.47 \\
\hline IR Beam Break & 6 & 8 & 9 & 7 & 8 & 6 & 44 & 7.42 \\
\hline Precision Ultrasonic & 5 & 3 & 5 & 7 & 3 & 6 & 29 & 4.43 \\
\hline
\end{tabular}

\section{Full System Research}

\section{Equipment Decisions}

Based on the research and analysis performed in previous stages, it is determined that the best sensor to be used in the full-scale operation of an electronic tennis officiating system is a LiDAR rangefinder. This is because it is accurate, relatively inexpensive, small in size, reliable, and has a very fast reading refresh rate, all making it an ideal piece of equipment.

In terms of peripheral equipment, the Punch Through Light Blue Bean+ will be used to connect the LiDAR sensors to the main central system. It was determined to be the best option based on its ease of use, low cost, and high functionality from being a mini microcontroller itself. 
As the main component for the entire system, an Arduino Mega microcontroller will be used. This is the larger version of the previously investigated Arduino Uno board. It was seen as the best option because it is easy to use, provides a large support community for troubleshooting, is very inexpensive and provides a large number of $\mathrm{I} / \mathrm{O}$ ports to connect other devices to it.

For an alert system, a combination of options will be utilized in the final full-scale design. This will include an LED light system, as well as an LCD display. The LED light system was chosen because it can be easily seen by an official from out of their peripheral vision, ensuring they can go back and forth from watching the match and looking for calls made by the system. This element is essential, as an official needs to make other calls during the match for things such as interference, hindrance, code violations and time violations. However, in order to give greater peace of mind to a roving chair umpire, the LCD display will also be used to convey more detailed information that can be viewed before or after a point. This could include whether the right service position or sensing mode is in use, as well as what the last call made by the system was.

For the cases and holders, it was determined that 3D printed designs would be the best option for the full-scale system. This was due to the fact these units could be highly customized, could be made out of many different flexible materials, requires the least amount of construction and assembly, and is relatively inexpensive compared to other options.

\section{$\underline{\text { Set-Up Options }}$}

There are a few different possibilities when it comes to how the sensors will be used with one another, how many of them there are, and what their court placement will be. The first would involve using one sensor per line per side. In this configuration, one sensor would be placed on 
the back or outside edge of each line for both sides of the court, totaling 8 LiDAR rangefinders. The system would only alert the official if the ball, or foot during a serve, touches the outside portion of the line. This would be beneficial due to the fact it is easy to set-up and provides somewhat close proximity calls to all lines. However, this would require the purchase of a moderate number of sensors overall, making the cost higher and increasing the complexity of the system. Also, only really close calls would be made, meaning calls that are slightly less obvious would not be called, reducing the peace of mind for the chair or roving umpire.

Another similar system that could be used involves one sensor per line. This would involve a LiDAR rangefinder for each sideline, with balls being called through the net, as well as one on each base and service line. In order for the system to function, 6 sensors would need to be purchased, and small holes would need to be cut in the net for pass-through readings. This is beneficial due to the fact it requires less sensors to function, lowering the overall cost and complexity. Additionally, it would make it easier for people to setup, even if they are not familiar with the technology. However, because the system would require modifications to the nets, it would likely be unpopular with clubs because of their unwillingness to change or possibly damage their existing equipment. Furthermore, there would be a reduction in accuracy and reliability because the setup would increase the likelihood of interference from outside factors, such as wind, dirt, garbage, opposing players' feet and loose balls, while calling lines on both sides of the net.

The final system option involves having multiple sensors for every line on each side of the net. Between 2 and 4 LiDAR rangefinders would be placed on the line, with at least one on the inside and one on the outside portion of it, as well as one outside the line itself. The system would not only call balls in, but also call them out, which is a change from previously discussed 
options. In total, there would be between 16 and 32 sensors required for one court. This system is beneficial because it provides greater peace of mind for officials, with it being able to make both obvious and close calls for them. It would also provide superior accuracy due to the fact a call would rely on multiple inputs to make a determination as opposed to just one. However, this setup would be extremely costly, making it less affordable for clubs and organizations to purchase and use. Furthermore, it would increase the complexity of the entire system, meaning there would be a greater chance of malfunction, and therefore less reliability.

In the end, the goal of the entire project is to find something that is low cost, accurate and reliable. Therefore, in an effort for balance these elements while providing the best option possible for end users, the first system using one sensor per line per side of the court will be used. It ensures a relatively low cost from having to purchase less sensors, greater accuracy from mounting rangefinders on both sides of the court close to the actual lines, and better reliability from having less total components working together.

\section{$\underline{\text { Potential Obstacles }}$}

There are a few different factors that could provide problems during the setup and operation of an electronic tennis officiating system. First of all, there are the different court surfaces used at different clubs and tournaments, including concrete, clay, grass and carpet. This means there could be interference from bumps, mounds of clay or higher grass, requiring sensors to be placed at different heights depending on the venue. Furthermore, hard concrete courts can become very hot, especially during the summer months outdoors. This may cause sensors to melt or malfunction during operation. 
Another obstacle involves the movement of players and officials on court. Players run to all different places within and outside the lines of the court during a match, and their feet and/or racquet may get in the way of sensors and interfere with calls. Furthermore, players could potentially trip over the sensors if they are positioned too close to the court.

Additionally, there is the issue of court dimensions. The actual lines of the court are always a standard size, but the area outside of them vary depending on the venue. Because of this, pre-set distance thresholds programmed into the system for the rangefinders may not correspond to the actual position of the lines on the court. Also, courts can be placed relatively close together at smaller venues, meaning there is little space between them to put sensors so that they do not interfere with play.

Outside factors can also play a role in interfering with the system. Stray balls, insects, small animals, dirt and even garbage can get in front of the devices, making them provide false readings and therefore bad calls.

Finally, there are the restrictions associated with the rules of the game. Outside devices in and around the court and net must be kept to an absolute minimum, and are sometimes banned, in order to minimize potential interference (Tennis Canada, 2017). This includes having nothing within the standard dimensions of the actual court and nothing mounted above or beside net posts (Tennis Canada, 2017). This limits the potential placement of sensors due to the fact they must be far away from the lines and the net.

\section{Overcoming Obstacles}

There are some considerations that can be made in order to ensure obstacles can be overcome by the system. Firstly, for distance sensors, specific thresholds will be made for 
alerting that only encompass the lines of the court. This will ensure that anything inside or outside the lines will not be sensed by the LiDAR rangefinders, therefore reducing the impact of player movement and outside factors.

Also, sensors will be mounted on secure devices that cover and hold them in place. This will somewhat shield them from the heat of the court, therefore protecting them from damage. Furthermore, they will be made from bright coloured materials so they are easy for players to see and therefore avoid during the match.

Finally, sensors will be placed outside of the restricted dimensions area of the tennis court. This ensures compliance with the rules of tennis federations and tournaments and makes it less likely any interference will occur during matches.

\section{Commercialization}

\section{Market Analysis}

As of 2014, it was reported that 101 million people play tennis around the world (Gadkari \& Wilson, 2014). In the United Kingdom and United States, two of the largest tennis playing countries in the world, the industry is worth $\$ 5.6$ billion (USD) and $\$ 2.5$ billion (USD) respectively (Gadkari \& Wilson, 2014). Additionally, in 2015, the 5 major tennis tournaments, known as the 'Grand Slams,' combined for 2.3 million attendees, \$873 million (USD) in revenue and \$138 million (USD) in prize money (Carter, 2016). With all of this in mind, it is clear that tennis is both popular and profitable, making it an ideal market to sell new products into.

Currently, there are no professional level live electronic line calling systems for tennis on the market. The only indirect competitor of this new system would be HawkEye. 
HawkEye, which was discussed in previous sections, currently has an advantage in the market today due to the fact they have been operating in the sports world for years. The company has built up relationships in tennis with the Association of Tennis Professionals (ATP), Women's Tennis Association (WTA), and International Tennis Federation (ITF), as well as tennis federations from the United States, Canada, France, Australia, the United Kingdom, and many other countries around the world (Hawk-Eye Innovations, 2015). Furthermore, their technology is viewed as the market standard, and is trusted at tournaments of all levels (Hawk-Eye Innovations, 2015). Additionally, the company has great brand recognition, not just in tennis, but also in soccer, volleyball, cricket, football, hockey, rugby, and baseball, to name a few (HawkEye Innovations, 2015). Finally, the company has a large amount of resources, from their large pool of employees, to the millions of dollars in revenue they accumulate each year (Kavanagh, 2015). With all of this in place, it is likely HawkEye has the ability to retaliate against new firms by developing their own version of a live line calling product and marketing it extensively.

To be successful, and compete within the global tennis market, it will be of critical importance for the new electronic tennis officiating system to focus on its two main advantages and points of differentiation; live calling and low cost. This will ensure prospective customers are aware of the full capabilities of the system, and will provide a point of comparison when they look at other, somewhat similar systems and methods.

\section{$\underline{\text { Costs }}$}

A thorough cost analysis was performed involving the prices and quantities of every component used within the newly created electronic tennis officiating system. The best options for each component were selected from a variety of different sources, including RobotShop, Creatron, Amazon, PunchThroug and Custom Prorotype's Hub. In total, the basic cost of the 
system was calculated to be $\$ 3730.99$. This amount is quite substantial due to the fact all of the required parts would be purchased at retail prices. In the future, when multiple systems are being built at the same time, costs will likely diminish due to volume discounts given by suppliers when ordering several units of each component at on time.

\section{TABLE 2:}

\begin{tabular}{|c|c|c|c|c|c|}
\hline \multicolumn{6}{|c|}{ Electronic Tennis Officiating System Components Costs } \\
\hline Component & Source & Price & Quantity & & Cost \\
\hline LiDAR rangefinders & RobotShop & $\$ \quad 170.99$ & 8 & & $1,367.92$ \\
\hline Arduino Mega & RobotShop & 45.99 & 1 & $\$$ & 45.99 \\
\hline Bluetooth Bean+ & PunchThrough & 55.00 & 9 & $\$$ & 495.00 \\
\hline 3D Printed Control Panel & Custom Prototype's Hub & $\$ \quad 376.42$ & 1 & $\$$ & 376.42 \\
\hline 3D Printed Bean Holder & Custom Prototype's Hub & 96.46 & 1 & s & 96.46 \\
\hline 3D Printed LiDAR Cases & Custom Prototype's Hub & $\$ 100.00$ & 8 & \$ & 800.00 \\
\hline Buttons & RobotShop & 0.64 & 2 & \$ & 1.28 \\
\hline Switches & RobotShop & 2.07 & 2 & $\$$ & 4.14 \\
\hline $10 \mathrm{~mm}$ RGB LEDs & Creatron & 1.90 & 2 & $\$$ & 3.80 \\
\hline $10 \mathrm{~mm}$ Green LEDs & Creatron & 0.35 & 6 & $\$$ & 2.10 \\
\hline Jumper Wire & RobotShop & 5.06 & 2 & $\$$ & 10.12 \\
\hline Lead-Free Solder & RobotShop & 11.54 & 0.25 & $\$$ & 2.89 \\
\hline Velcro & Amazon & 28.00 & 1 & $\$$ & 28.00 \\
\hline Resistors & RobotShop & 10.19 & 0.25 & 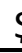 & 2.55 \\
\hline Electrical Tape & RobotShop & 1.70 & 0.5 & $\$$ & 0.85 \\
\hline Power Cord & Amazon & 20.73 & 1 & $\$$ & 20.73 \\
\hline USB Cord & Amazon & 7.52 & 1 & $\$$ & 7.52 \\
\hline 9V Batteries & Amazon & 3.24 & 9 & s & 29.16 \\
\hline $9 \mathrm{~V}$ battery holders & Amazon & 0.76 & 9 & $\$$ & 6.84 \\
\hline Subtotal & 1 & 1 & 1 & & $3,301.76$ \\
\hline $\operatorname{Tax}(13 \%)$ & I & l & l & & 429.23 \\
\hline Total & 1 & 1 & 1 & $\$$ & $3,730.99$ \\
\hline
\end{tabular}




\section{Development and Marketing}

After speaking with a tournament director, it was confirmed that the Ontario Tennis Association (OTA) would like to help in the further testing and development of the system. This would be done by installing the full scale, wireless version on one of the indoor courts at their facility within York University, to be used during matches at junior level tournaments in the winter. The system would only be used as a backup, with either a roving or chair umpire also keeping an eye on the match to ensure correct calls are being made. Problems with the system could be identified throughout, with previously unforeseen scenarios coming about during tournament play. In between days and tournaments, changes could be implemented and additional components could be added, allowing for better operation over time. Furthermore, during this process, the opinions and sentiments of players, coaches, officials, and tournament organizers could be assessed, leading to better information regarding how the system could be improved upon and marketed in the future.

Once the system gets to a level of suitable reliability and accuracy, a larger launch could be done. At this point, many clubs and federations would likely have seen or heard of the system, ensuring a wider interest in its installation at additional locations. The relationships fostered at the OTA could then be leveraged to persuade other facilities and organizations to install the system at their events as well. To help prospective buyers better understand the technology, and allow them to easily contact or order from the newly formed company, a website would be created. It would include details about the sensors used, basic operation instructions, accuracy and reliability measurements, testimonials from tournament directors at the OTA, pricing guides, and ways to contact a representative for additional information or ordering. At the same time, a 
search marketing campaign would be initiated within the Google AdWords system to garner additional traffic from those who may be unfamiliar with the product.

\section{Pricing}

There are two potential revenue models that could be implemented when generating revenue from the system; leasing and purchasing.

Within the leasing option, tournaments, clubs and federations would pay to rent the system equipment for a specified period of time, between one day and two weeks. This option would be suited for scenarios involving short term events taking place, where organizers only need the system in place for a few days at a time. A technician would come in and install the system on the desired courts and stay at the facility for the duration of matches in order to deal with issues encountered. Utilizing this model would likely make the system more popular with prospective customers as there is no capital expenditure requirement and low overall rental costs. Furthermore, it would give tournament organizers greater peace of mind knowing that a technician is always on hand to deal with problems that may occur.

A reasonable price for the rental of a system would be $\$ 250$ per 8-hour day, per court. Should more than one court be requested, small, incremental volume discounts would apply based on the fact that a technician could oversee at least 4 courts at a time during a given day, with minimal adjustments and repairs being required throughout matches. This price would allow the technician to be paid a reasonable $\$ 18$ per hour, or $\$ 150$ per day, and for the system to therefore make back $\$ 100$ per day, per court. Overall, this would mean the system could potentially break even at only 37 total days of operation, with almost pure profit being seen after that point. 
For the purchase option, a customer would buy the entire system outright. A technician would initially come to install it, provide the owner with a basic tutorial, and answer any questions they may have. There would be a defined 6-month warranty on the system, wherein customers could call a technician and have them come to fix any technical problems at no additional charge. Beyond this timeframe, an extended warranty of 12 months or 18 months could be purchased if desired. Once the warranty expires, any issues requiring a technician to come and perform maintenance or more extensive repairs would cost the owner a fee, depending on what parts were used and the amount of time the employee spent working on it.

This option would be suited for individuals that have a tennis court at their house, or clubs that want to use the system as an added feature to their court rentals for members. The benefit of this option for the company is that the entire system would be paid for in full, so all costs could be covered immediately after purchase. Furthermore, it would not require a technician to be onsite at all times, lowering the variable costs of system use over time. Also, with the additional options of an extended warranty, more revenue could be generated over time, on top of the money paid for the initial system itself. However, the purchase option would likely not be popular with most prospective buyers as it requires a large capital expenditure. Additionally, customers are not given the peace of mind associated with having a technician constantly on site to deal with issues, which could lead to some purchase anxiety.

Based on the cost of $\$ 3730.99$, a reasonable price to buy the entire system would be $\$ 5000$. This amount is justified by the fact since the system used advanced technology, is incredibly accurate, can replace large crews of umpires making $\$ 120$ per day each, can be used in replacement of a $\$ 10,000$ or more per week per court HawkEye system, and has a likely 
lifespan of several years. Given an installation of 4 hours, and an estimate of 2 warranty covered service trips of 2 hours each, the initial profit seen from the sale would be $\$ 1125.01$.

For the extended warranties, a total of $\$ 250$ would be charged for 12 total months of coverage, and $\$ 400$ would be charged for 18 months of total coverage. Based on the estimate of 3 service calls between the $7^{\text {th }}$ month and $12^{\text {th }}$ month, as well as between the $13^{\text {th }}$ month and $18^{\text {th }}$ month, a total of $\$ 108$ would be spent on the 12 -month warranty, and $\$ 216$ would be spent on the 18-month warranty. This would leave approximately $\$ 142$ and $\$ 184$ in profit for the extended warranty plans respectively.

\section{Final Deliverable}

The goal of this stage was the show the different types of sensors and components researched and tested throughout the entire process. It was decided that at least one of each sensor and multiples for better working devices to ensure reliable operation during the exhibition. 2 LiDAR rangefinders, 2 IR distance sensors, 3 IR beam break devices and 1 precision ultrasonic proximity sensor were used in the final design. An effort was made to ensure sensors were on both a horizontal and vertical line in order to show the full capabilities of each one. Additionally, a Bluetooth bean was mounted to the net to detect net vibration during serves, and provided a wireless element to the entire system.

LEDs were used as the primary system communication method for the operator. 6 green ones were used for service and long lines and 2 RGB ones were used on the baseline so that either a red or green light would show depending on whether or not a foot fault was called during service or a ball was called in during a rally. As a backup, the LCD screen was added to act as a failsafe and provide peace of mind to the operator. It shows that the system and its functions are 
operating correctly and also displays the last call made, in case an umpire missed seeing a light at the end of the point.

2 switches were used to dictate where the serve was coming from, with a far/near option and a left/right option. 2 push button switches were used to operate different functions within the program. The left button would be used first for service, and the right button would be used for rallies during the point. A slightly larger Arduino Mega microcontroller was utilized in order to provide more I/O ports for sensors and LEDs.

Finally, LEDs, switches, and buttons were mounted to the 3D printed control panel for easy operation. Also, the Bluetooth bean was put inside of a 3D printed case that could be mounted to the net.

\section{Operating Instructions}

When the microcontroller is powered on, the LCD screen will display an initialization message. The user can then use the switches to tell the system where the serve is coming from. The top switch dictates whether it is coming from the near or far portion of the court, and the bottom button dictates whether it is coming from the left or right side of the court.

To initiate the serve function, press and hold the left button until just after the ball has hit the court. Then, to initiate the rally function, press and hold the right button until the point is complete. A red light will be turned on if a foot fault is detected during service. A green light will be turned on if an in call is made on a particular line. To check the last call made, release one of the buttons and look at the second line on the LED screen. 


\section{Reflection}

Going from full scale testing to a much smaller scale design for the showcase was difficult in many ways. Firstly, some of the sensors did not work well at shorter distances, especially the precision ultrasonic. Anything less than 1 meter was not usually picked up by the sensor, which made it problematic to build into the system. Also, putting the thresholds into the code proved quite challenging. This was due to the fact the sensors' outputs usually jumped around by a few millimeters in any given second during operation. With such a small sized scale model court, a few millimeters meant the difference between a ball being far inside, to very outside the line. Therefore, exact calls could often not be made without a few false positive blips on the LEDs.

Another problem involved consolidating the code from all of the different sensor tests into the full system. Organizing everything so it would be easy to go back and make changes was difficult. At different points, more spaces and notes had to be added so that it wasn't too confusing to go through. One strategy that helped involved creating a document outlining the positioning of different sensors and the pins being used for components. That way, if anything ever came unhooked or was not working properly, someone could easily go back and ensure all of the values were correct and all wires were in the correct place.

In an effort to minimize the number of issues seen after everything was built and coded together, it was started in stages. This involved adding sensors one at a time to the final code, creating the simplest system first before adding more functionality. Whenever another sensor was added, a test was performed to make sure the correct values were being read and the right LEDs were going off at different thresholds. 
The original level 1 complete design had every sensor looking at and responding to what was happening on the scale model court, without any specifications made for rally and serve modes. While it would not be functional during actual operation, it was quite good for initial testing. For the level 2 design, the rally and serve buttons, as well as the serve positioning switches were added so alerting could be better controlled by the user. The final level 3 design added functionality for the LCD screen, which included a reading for the current mode as well as the last in call made. It featured the addition of LCD, Liquid Crystal, I2C and Wire libraries.

Originally, there was a plan to print 3D designs on printers at the Ryerson Student Learning Centre Digital Media Experience Lab. However, it was quickly realized after an introductory session with the staff there that the designs were too large and complex to print using the machines and materials available there. The light and switch holder was estimated to take approximately 27 hours to print and the many overhangs would need to be significantly reinforced. Additionally, the Bluetooth bean holder involved parts that were too small to realistically be sturdy enough based on their positioning within the design using the supplied materials. Eventually, after speaking with some different companies, it was determined that the best option would be to get the designs professionally 3D printed using a large, industrial, high capacity machine. The technician at Toronto based Custom Prototype's Hub felt that 50-micron nylon material printed using the selective laser sintering (SLS) technique would be the ideal option. This was due to the fact the material would be strong enough to not require reinforcement of overhanging and small parts, and would provide exact enough detail to fit my small components, including LEDs, switches and buttons.

Finally, the actual transportation of the device to the showcasing area proved extremely difficult. Originally, the desire was to carry the entire system intact to the exhibition hall. 
However, it was determined that could not be done based on the pure size and complexity of the system design, so it needed to be somewhat disassembled before being moved. Because there were so many components connected together, it was hard to take everything apart and keep it organized so the system could be rebuilt after transportation. Furthermore, it was difficult to find something to keep the sensors in position so that they could be easily taken off and put on again later in the day. Velcro, clips and several types of tape were tried, but in the end, a combination of painter's tape and Velcro was used, in addition to felt pads to ensure all of the sensors were perfectly level. 
Appendix A: Pictures of Project Progress

Basic Proof of Concept
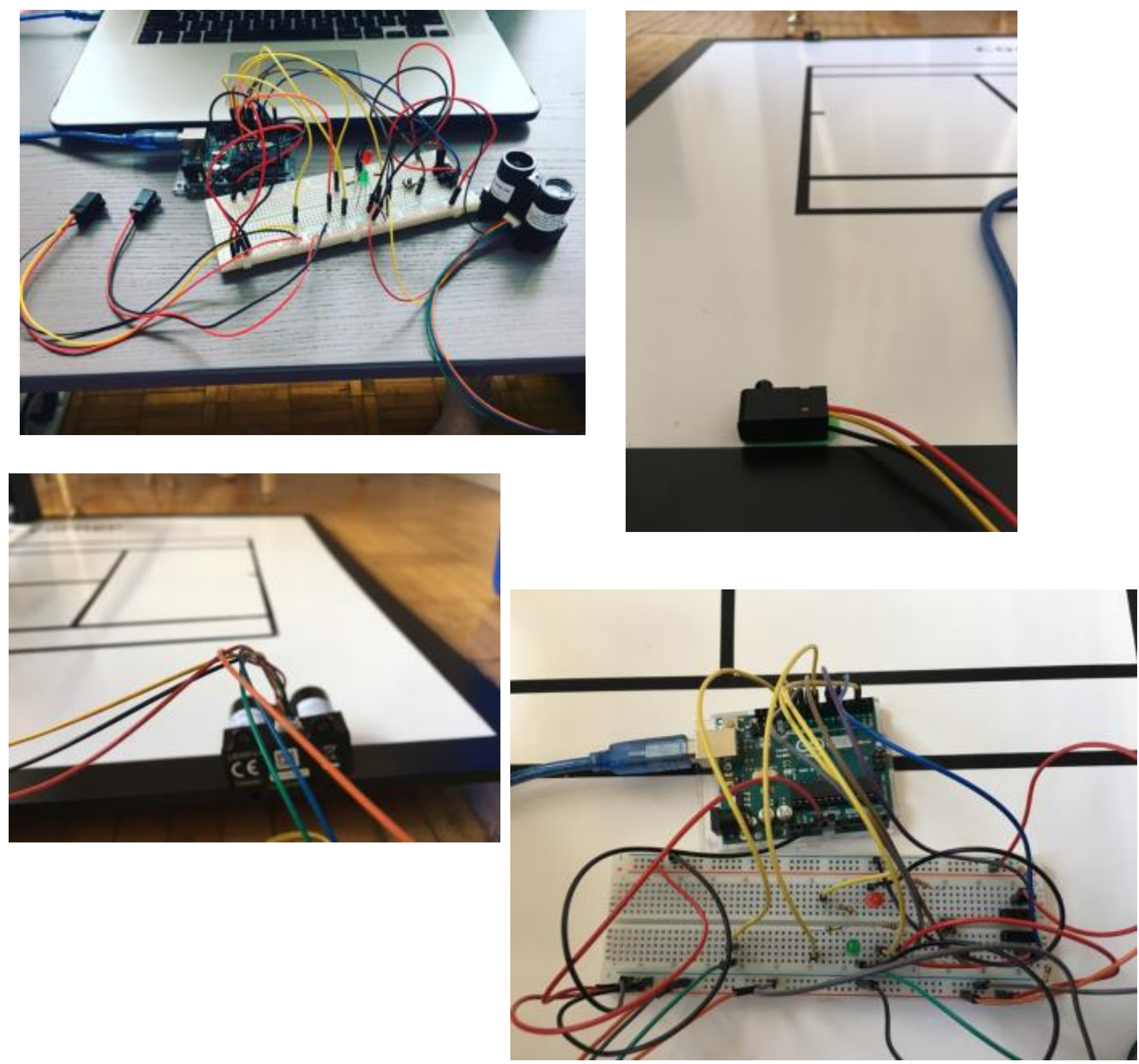

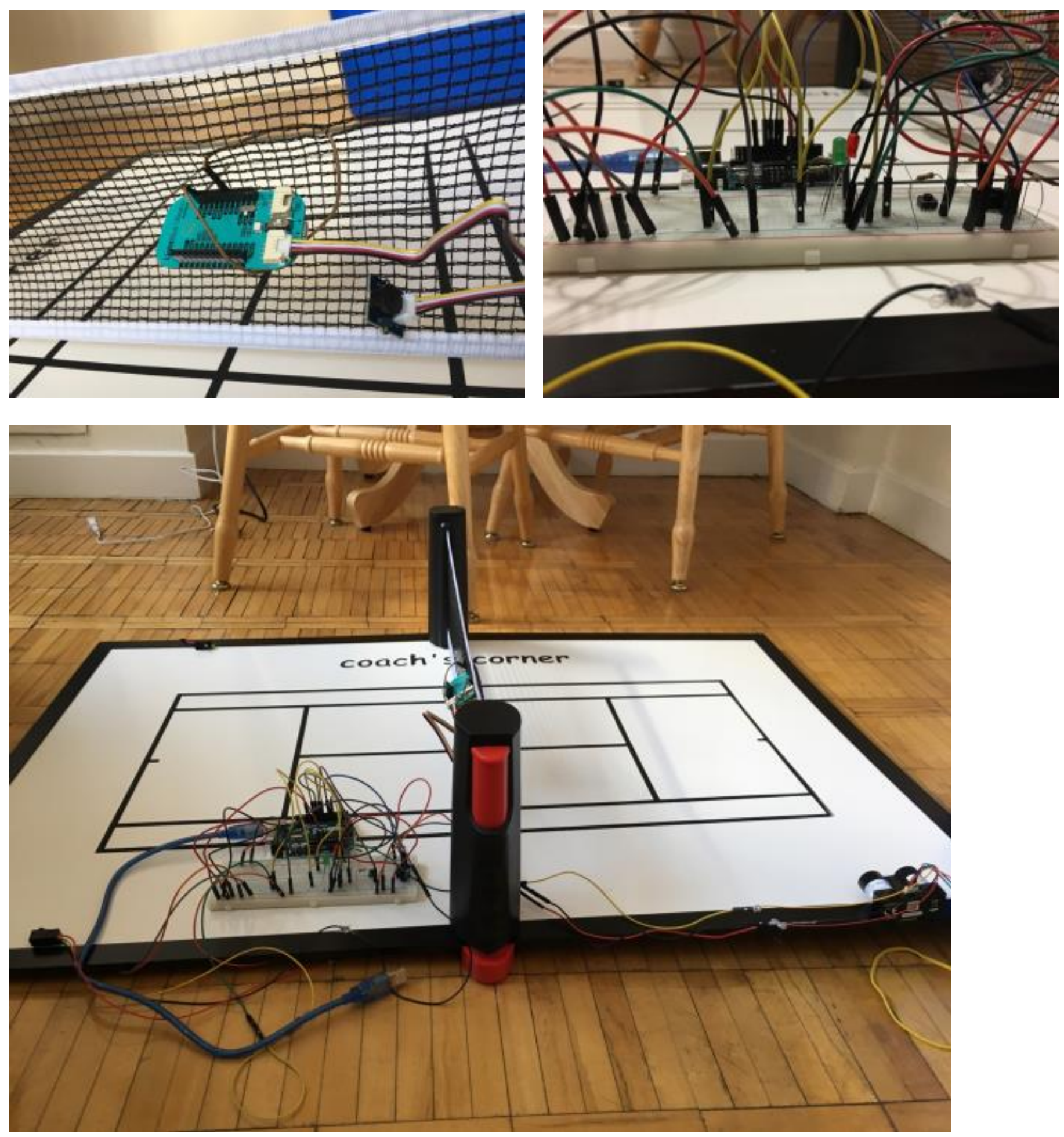
Final Deliverable
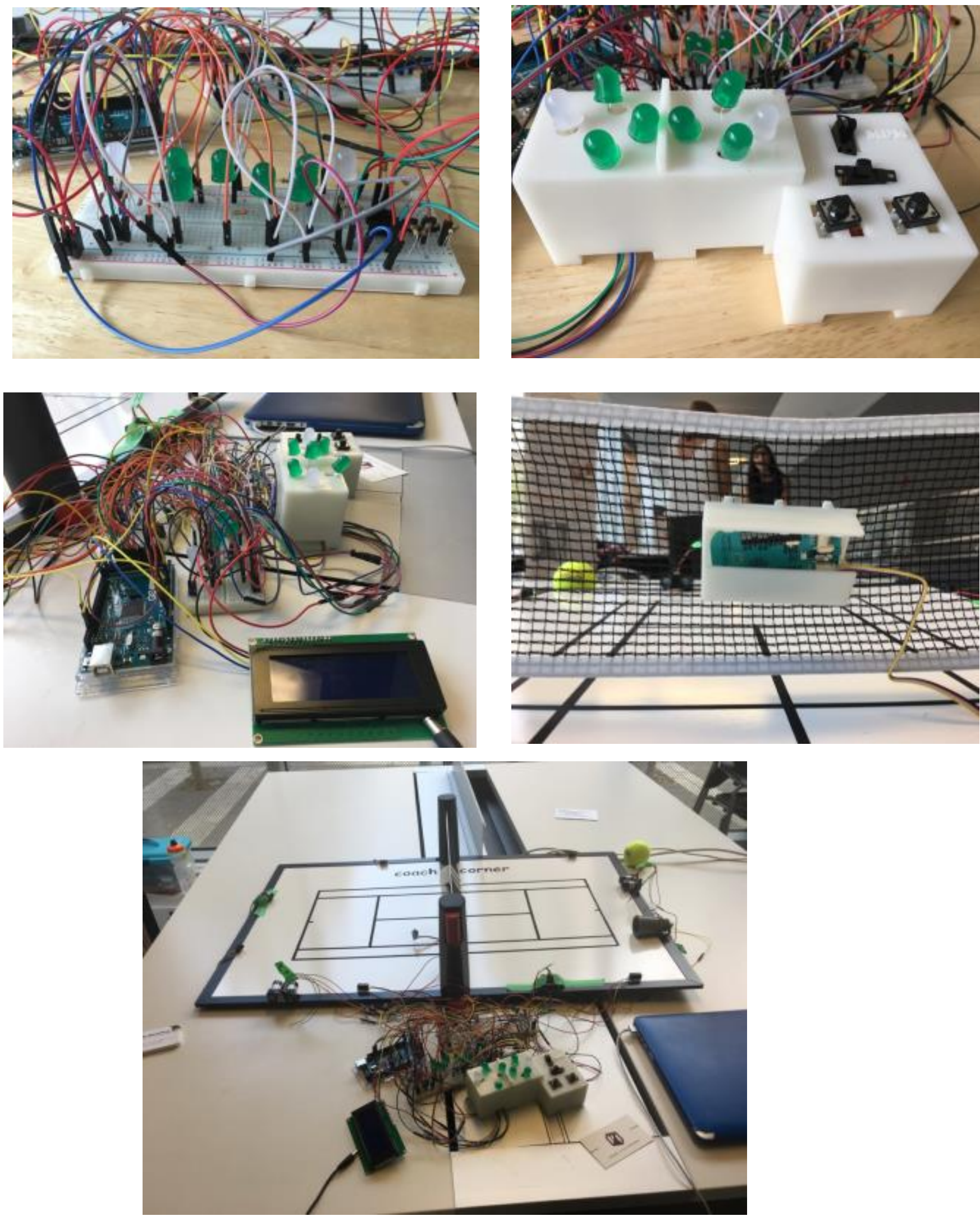


\section{Appendix B: 3D Component Design Images}
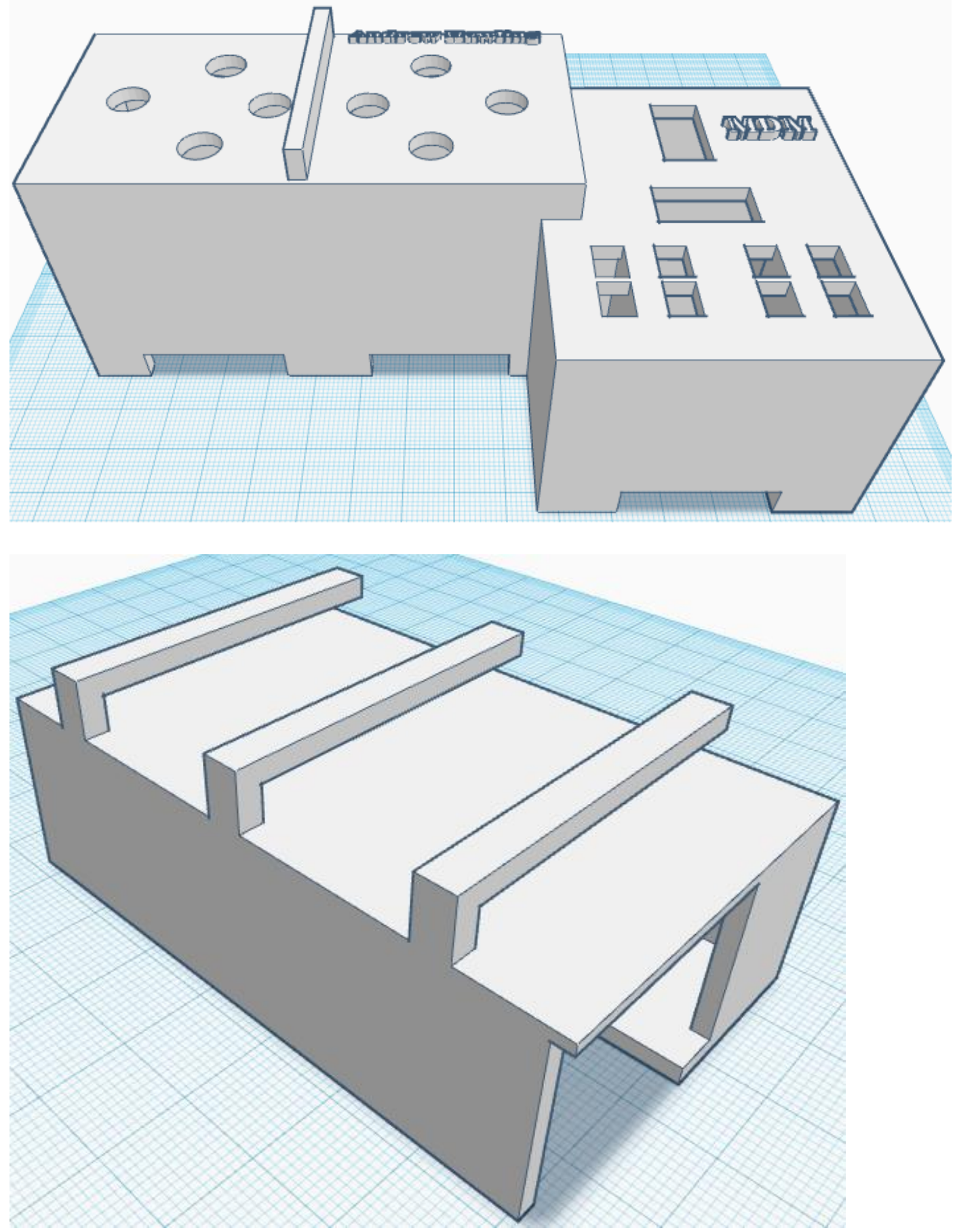


\section{References}

3D Printing For Beginners. (2013, February 12). What Material Should I Use For 3D Printing? Retrieved from http://3dprintingforbeginners.com/filamentprimer/

Adafruit. (2015, May 4). IR Beam-Break Sensors. Retrieved from https://learn.adafruit.com/irbreakbeam-sensors/overview

Adafruit. (n.d.). IR Distance Sensor - Includes Cable (100cm-500cm). Retrieved from https://www.adafruit.com/product/1568

Amazon. (n.d.). C\&E CNE02608 USB 2.0 6-Feet Printer Cable Cord A-B. Retrieved from https://www.amazon.ca/gp/product/B0032GTLH2/ref=oh_aui_detailpage_o04_s00?ie= UTF8\&psc $=1$

Amazon. (n.d.). Duracell Coppertop 9V Alkaline Batteries. Retrieved from https://www.amazon.ca/gp/product/B00622F5QO/ref=oh_aui_detailpage_o04_s00?ie=U TF8\&psc $=1$

Amazon. (n.d.). Super Power Supply AC / DC Adapter Charger Cord Plug - 9V 650mA compatible with Arduino. Retrieved from https://www.amazon.ca/Super-Power-SupplyAdapter-

Charger/dp/B00BWA48AA/ref=sr_1_6?s=electronics\&ie=UTF8\&qid=1503612185\&sr $=1-6 \&$ keywords=arduino+power+cord

Amazon. (n.d.). VELCRO Brand - Industrial Strength - 2" Wide Tape, 15' - Black. Retrieved from https://www.amazon.ca/VELCRO-Brand-Industrial-StrengthBlack/dp/B00006RSP1/ref=sr_1_4?ie=UTF8\&qid=1503612001\&sr=8$4 \&$ keywords $=$ velcro 
Amazon. (n.d.). URBEST Black Faux Leather Shell T Type Wired 9V Battery Clip Connector. Retrieved from https://www.amazon.ca/gp/product/B00ME39SXG/ref=oh_aui_detailpage_o04_s00?ie= $\mathrm{UTF} 8 \& \mathrm{psc}=1$

Arduino. (2013, September 18). Will IR sensors be affected by sunlight? Retrieved from http://forum.arduino.cc/index.php?topic $=188618.0$

Arduino. (2014, July 6). Need help with Sharp IR Sensor GP2Y0A02YK0F. Retrieved June 30, 2017, from http://forum.arduino.cc/index.php?topic=253590.0

Arduino. (n.d.). ArduinoBoardUno. Retrieved from https://www.arduino.cc/en/Main/ArduinoBoardUno

BBC Sport Academy. (n.d.). Cyclops and speed guns. Retrieved from http://news.bbc.co.uk/sportacademy/hi/sa/tennis/features/newsid_3001000/3001768.stm

Carnegie Mellon University. (n.d.). What is an Ultrasonic Sensor? Retrieved from http://education.rec.ri.cmu.edu/content/electronics/boe/ultrasonic_sensor/1.html

Carnegie Mellon University. (n.d.). What is different about the Sharp IR Sensor? Retrieved from http://education.rec.ri.cmu.edu/content/electronics/boe/ir_sensor/4.html

Casas-Cartagena, M. (2016, September 12). Arduino Infra Red Sharp Lib. Retrieved July 5, 2017, from https://github.com/guillaume-rico/SharpIR

Carter, A. (2016, January 20). Grand Slam 2016: Tennis' Four Majors By The Numbers. Retrieved from https://www.forbes.com/sites/alikocarter/2016/01/20/grand-slam-2016tennis-four-majors-by-the-numbers/\#1c2c489d7b0a 
Creatron. (n.d.). 10mm LED - Green. Retrieved from https://www.creatroninc.com/product/10mm-led-green-5pack/?search_query $=10 \mathrm{~mm}+$ led+green $\&$ results $=4$

Creatron. (n.d.). 10mm LED - RGB. Retrieved from https://www.creatroninc.com/product/10mm-led-rgb$\mathrm{cc} /$ ?search_query $=10 \mathrm{~mm}+\mathrm{led}+\mathrm{rgb} \&$ results $=2$

Custom Prototype's Hub. (n.d.). 3D Printing \& Rapid Prototyping Services Toronto. Retrieved from https://www.customprototypes.ca/

DFRobot. (2017, June 29). I2C TWI LCD2004 Module. Retrieved June 30, 2017, from https://www.dfrobot.com/wiki/index.php/I2C_TWI_LCD2004_Module_(Arduino/Gadg eteer_Compatible)_(SKU:DFR0154)

Di Justo, P. (2015, December 4). Raspberry Pi or Arduino? One Simple Rule to Choose the Right Board. Retrieved from http://makezine.com/2015/12/04/admittedly-simplisticguide-raspberry-pi-vs-arduino/

Dikmans, L. (2015, August 7). Programming languages for Raspberry Pi. Retrieved from http://www.eproseed.com/programming-languages-for-raspberry-pi/

Electrical Engineering Stack Exchange. (2011, April 28). Which programming languages are supported to program Arduino? Retrieved from https://electronics.stackexchange.com/questions/13616/which-programming-languagesare-supported-to-program-arduino/13621\#13621

Engineer Experiences. (2016, October 1). Advantages and Disadvantages of Using Arduino. Retrieved from http://engineerexperiences.com/advantages-and-disadvatages.html 
ESAB. (2013, July 29). How Does Laser Cutting Work? Retrieved from www.esabna.com/us/en/education/blog/how-does-laser-cutting-work.cfm

Gadkari, P., \& Wilson, B. (2014, January 22). The global tennis industry in numbers. Retrieved from http://www.bbc.com/news/av/business-25824824/the-global-tennis-industry-innumbers

Garmin. (2016, September). Lidar Lite v3 Operation Manual and Technical Specifications. Retrieved from https://static.garmin.com/pumac/LIDAR_Lite_v3_Operation_Manual_and_Technical_S pecifications.pdf

Garmin. (2017, January 25). LIDARLite v3 Arduino Library. Retrieved July 7, 2017, from https://github.com/garmin/LIDARLite_v3_Arduino_Library

Giges, N. (2014, August). Top 10 Materials for 3D Printing. Retrieved from https://www.asme.org/engineering-topics/articles/manufacturing-processing/top-10materials-3d-printing

Ginn, L. (2011, March 9). Indian Wells event puts it all on line: Hawk-eye on every court. Retrieved from https://usatoday30.usatoday.com/sports/tennis/2011-03-09-bnp-paribasopen-hawkeye_N.htm

Greenman, C. (2000, August 31). For U.S. Open Tennis, a Service Line Umpire That Never Blinks. Retrieved from http://www.nytimes.com/2000/08/31/technology/for-us-opentennis-a-service-line-umpire-that-never-blinks.html

Hawk-Eye Innovations. (2015). Electronic Line Calling FAQ. Retrieved from https://www.hawkeyeinnovations.com/products/ball-tracking/electronic-line-calling 
Hawk-Eye Innovations. (2015). Hawk-Eye Innovations Tennis. Retrieved from https://www.hawkeyeinnovations.com/sports/tennis

Indian Institute of Technology Kanpur. (n.d.). Advantages of LiDAR technology. Retrieved from http://home.iitk.ac.in/ blohani/LiDAR_Tutorial/AdvantagesofLiDARtechnology.htm

Kavanagh, M. (2010, August 31). Hawk-Eye ball-tracker developer put up for sale. Retrieved from https://www.ft.com/content/44f114b0-b532-11df-9af8-00144feabdc0

Malpartida, F. (2015, October 24). New Liquid Crystal. Retrieved July 15, 2017, from https://bitbucket.org/fmalpartida/new-liquidcrystal/downloads/

Maxbotix. (2012). HRXL-MaxSonar-WRS Sensor Series. Brainerd, MN: Author.

Maxbotix. (2017). Using a MaxSonar with an Arduino. Retrieved from https://www.maxbotix.com/Arduino-Ultrasonic-Sensors-085/

Orlin, J. (2012, October 21). Getting Started With The Raspberry Pi Is Not As Easy As Pie. Retrieved from https://techcrunch.com/2012/10/21/getting-started-with-the-raspberry-piis-not-as-easy-as-pie/

Pololu Robotics and Electronics. (n.d.). Materials for Laser Cutting. Retrieved from https://www.pololu.com/docs/0J24/3

Punch Through. (n.d.). LightBlue Bean+. Retrieved from https://store.punchthrough.com/collections/bean-family/products/lightblue-beanplus?_ga=2.6832570.98022425.1503599724-2045119338.1490653571

Punch Through. (n.d.). Welcome To Bean. Retrieved from https://punchthrough.com/bean/docs/guides/getting-started/intro/ 
Raspberry Pi Foundation. (2016, February). Raspberry Pi 3 Model B. Retrieved from https://www.raspberrypi.org/products/raspberry-pi-3-model-b/

Roberts, J. (1995, November 23). Cyclops has company as machine moves to replace net cord judge. Retrieved from http://www.independent.co.uk/sport/cyclops-has-company-asmachine-moves-to-replace-net-cord-judge-1583317.html

Robo India. (2017, July 19). I2C LCD on Arduino. Retrieved from https://roboindia.com/tutorials/i2c-lcd-arduino

Robot Shop. (2017). LIDAR-Lite 3 Laser Rangefinder. Retrieved from http://www.robotshop.com/ca/en/lidar-lite-3-laser-rangefinder.html

Robot Shop. (n.d.). 1/4W Resistor Kit. Retrieved from http://www.robotshop.com/ca/en/1-4wresistor-kit-500pk.html

Robot Shop. (n.d.). 12mm Push Button Switch. Retrieved from http://www.robotshop.com/ca/en/sfe-12mm-push-button-switch.html

Robot Shop. (n.d.). 5mm Copper Electrical Tape. Retrieved from http://www.robotshop.com/ca/en/5mm-copper-tape-50.html

Robot Shop. (n.d.). Arduino Mega 2560 Microcontroller Rev3. Retrieved from http://www.robotshop.com/ca/en/arduino-mega-2560-microcontroller-rev3.html

Robot Shop. (n.d.). Arduino Uno R3 USB Microcontroller. Retrieved from http://www.robotshop.com/ca/en/arduino-uno-r3-usb-microcontroller.html Robot Shop. (n.d.). HRXL-MaxSonar-WRS3 High Performance Ultrasonic Precision Rangefinder. Retrieved from http://www.robotshop.com/ca/en/hrxl-maxsonar-wrs3high-performance-ultrasonic-precision-rangefinder.html 
Robot Shop. (n.d.). Jumper Wires Premium 12" M / M Pack of 20. Retrieved from http://www.robotshop.com/ca/en/jumper-wires-premium-12-m-m-pack-of-20.html

Robot Shop. (n.d.). Lead Free Solder (100g). Retrieved from http://www.robotshop.com/ca/en/lead-free-solder-100g-vel.html

Robot Shop. (n.d.). Raspberry Pi 3 Computer Board. Retrieved from http://www.robotshop.com/ca/en/raspberry-pi-3-computer-board.html

Robot Shop. (n.d.). Tamiya Mini Power Switch. Retrieved from http://www.robotshop.com/ca/en/tamiya-mini-power-switch-2pk.html

Sharp. (n.d.). GP2Y0A21YK0F Distance Measuring Sensor Unit. Retrieved from http://www.sharpworld.com/products/device/lineup/data/pdf/datasheet/gp2y0a21yk_e.pdf

Sparkfun. (n.d.). Arduino Shields. Retrieved from https://learn.sparkfun.com/tutorials/arduinoshields

Tennis Canada. (2017). Rules of the Court. Retrieved from http://www.tenniscanada.com/wpcontent/uploads/2016/02/RULES-OF-THE-COURT-2017.pdf

Tennis Canada Officiating. (2017, January 16). Recommended Minimum Fee Schedule. Retrieved from http://mtl.tenniscanada.ca/TCOfficial/misc/documents\%202017/Recommended\%20min $\% 20$ fee\%20structure\%202017\%20January.pdf

Top Ten Reviews. (2016, November 18). Best IR Beam Sensors Review. Retrieved from http://www.toptenreviews.com/home/articles/best-ir-beam-sensors-review/

Vidvei, M. (n.d.). Get Started With Distance Sensors and Arduino. Retrieved from http://www.instructables.com/id/Get-started-with-distance-sensors-and-Arduino/ 
Walker, A. (2013, June 21). 3D printing for dummies: How do 3D printers work? Retrieved from http://www.independent.co.uk/life-style/gadgets-and-tech/features/3d-printing-fordummies-how-do-3d-printers-work-8668937.html 